\title{
A NOVEL PRESSURIZED ZONAL MODEL USING THE MOMENTUM EQUATION
}

\author{
${ }^{1}$ Yao Yu and ${ }^{2}$ Ahmed Cherif Megri \\ ${ }^{1}$ Department of Computational Science and Engineering, \\ ${ }^{2}$ Civil, Architectural and Environmental Engineering, CERT Research Center, \\ North Carolina A and T State University, NC 27411, Greensboro, USA
}

Received 2014-01-31; Revised 2014-03-03; Accepted 2014-03-25

\begin{abstract}
Zonal models combine the simplicity of single and multi-zone models with the comprehensiveness of Computational Fluid Dynamics (CFD) models and thus become a better substitute to predict detailed thermal and airflow behaviors in building. Based on a geometric partitioning of a room into a number of subzones, these models give more accurate and detailed results than the single or multi-zone modeling approaches and use less computer resource than CFD models. Nevertheless, most of the zonal models have to face a difficulty involving the limits of the simplification that need to be considered without losing accuracy and comprehensiveness. A new zonal model, called Pressurized zOnal Model using the Momentum Equation (POMME), has been developed, in which a simplified numerical model, representing various heat and mass transfer conservation equations is used. The program solver is similar to those used for CFD programs and is based on the finite-volume numerical techniques, the staggered grid formulation, the Semi-Implicit Method for Pressure-Linked Equations (SIMPLE) algorithm and other methods. The validation of this new zonal model has been accomplished by comparing its results with those obtained from the CFD software: PHOENICS. The results demonstrate not only the strength of the zonal model POMME in predicting the indoor airflow and thermal conditions, without the involvement of additional sub-models, but also its ability to provide relatively accurate results for building enclosures.
\end{abstract}

Keywords: Zonal Model, CFD, Jet Flow Model, Fluid Dynamics

\section{INTRODUCTION}

Zonal modeling approach was put forward, for the first time, based on experimental observations during the 1970s (Lebrun, 1970). For two decades, zonal models had slow developments. The most interesting works have been performed by (Inard and Molle, 1989; Inard and Buty, 1991; Inard et al., 1996a; 1996b; 1997a; 1997b). In fact, from the 1990s, different zonal models were developed. In particular, Bouia (1993) initiated the development of a new generation of zonal models, where the pressure field is predicted to determine the airflow and thermal behaviors over spaces. Wurtz (1995) put forth a new zonal model in which mass and energy balances were applied in each zone, while the mass flow rates at the interfaces were calculated using the power law as pressure relationship. Haghighat et al. (2001) developed a zonal model named Pressurized zOnal Model with the Air diffuser (POMA). They provided a comprehensive background and validation of this model, which is based on both mass and energy conservations and, as a simplified numerical model, uses pressure-driven power laws to estimate the mass flow rate between two subzones or cells instead of the momentum equations, usually used in Computational Fluid Dynamics (CFD) models. POMA is able to predict the airflow patterns and temperature distributions within a space. Jet characteristic equations were also introduced in the model in order to Corresponding Author: Yao Yu, Department of Computational Science and Engineering, North Carolina A and T State University,
NC 27411, Greensboro, USA 
generalize its application to mechanically ventilated rooms or buildings. In the same year, Axley (2001) developed an alternative formulation to model airflow resistance in zonal models, known as surface-drag flow relations for zonal modeling. This approach based on a surface-drag viscous loss mechanism is able to more accurately reflect the physical mechanisms of the airflow in natural convection situations. Griffith and Chen (2003) simplified the Navier-Stokes equations with the assumption of inviscid flow (Euler equations), reduced the mesh grid number and then proposed a momentum-zonal model to predict zone air flow and temperature distributions. As a matter of fact, the zonal modeling approach is considered as a halfway approach between single-zone (or multizone) and CFD models (Haghighat et al., 2001; Megri and Haghighat, 2007; Yu, 2012). This modeling approach can be used to predict the indoor airflow and thermal behavior, by geometrically subdividing a room into several zones, in which simplified equations are used to describe the transport phenomena. This approach is known to use less computational time than CFD models and is able to provide enough detailed results compared to single-or multi-zone models (Megri et al., 2005).

Although the zonal modeling approach has its benefits, the disadvantages cannot be ignored. Most of the zonal models have to face a difficulty involving the definition of a problem, because of the nature of the zonal models itself. Unlike CFD models, several separated additional sub-models, such as jet flow models, thermal plume models and so on, have to be accordingly included and numerically interconnected in a zonal model (Haghighat et al., 2001; Axley, 2001), in order to describe the transport phenomena. These submodels consist of several empirical equations, which are usually developed based on experiments. In addition, the inclusion of these sub-models into zonal modeling approach is relatively difficult. Therefore, the use and application of the zonal models into building environment are restricted by the limited number of these available sub-models, as well as the need of a strong background of related knowledge and expertise from the users to solve problems using the zonal models.

In this study, a new zonal modeling approach has been developed. Unlike the other zonal models, such as POMA (Haghighat et al., 2001), this new model allows the usage of a simplified one-dimensional momentum equation to replace the power law model in POMA. This model is valid for both natural convection and forced ventilation situations, without the involvement of additional sub-models. Thus, this new zonal model is called Pressurized zOnal Model using Momentum Equation (POMME). Different case studies have been demonstrated to illustrate the validity of this model in building applications. The program solver is similar to CFD programs and is based on the finite-volume numerical techniques, the staggered grid formulation, the Semi-Implicit Method for Pressure-Linked Equations (SIMPLE) algorithm and other methods. The validation of this new zonal model has been accomplished by comparing its results with those obtained from the CFD software: PHOENICS (2010).

\section{MATHEMATICAL DESCRIPTION OF THE NEW ZONAL MODEL}

In the original zonal model POMA (Haghighat et al., 2001), the mass flow rate is driven by a power law pressure relationship model:

$\dot{\mathrm{m}}_{\mathrm{ij}}=\rho \mathrm{kA}(\Delta \mathrm{P})^{\mathrm{n}}[\mathrm{kg} / \mathrm{s}]$

Where:

$\rho\left(\mathrm{kg} / \mathrm{m}^{3}\right) \quad=$ The fluid density

$\mathrm{A}\left(\mathrm{m}^{2}\right)=$ The cross-sectional area between two zones

$\Delta \mathrm{P}(\mathrm{Pa}) \quad=$ The pressure difference between two zones

$k\left(\mathrm{~m} \mathrm{~s}^{-1} \mathrm{~Pa}^{-\mathrm{n}}\right)=$ The flow coefficient, which is assumed to be 0.83 for all zones; $n$ is called flow exponent, which is 0.5

Based on a geometric partitioning of a room into a number of subzones, the power law model is used to describe the mass flow rate from one zone to another.

However, the original POMA is only suitable to simulate the natural convection cases. In order to use this zonal model in forced ventilation situations, additional sub-models, such as the jet flow model, have to be coupled with POMA (Haghighat et al., 2001; Megri et al., 2005; Jiru and Haghighat, 2004). Therefore, this additional coupling work not only increases the model complexity but also limits the application of the zonal model.

Equation 1 can be rewritten as follow:

$\mathrm{u}=\mathrm{k}(\Delta \mathrm{P})^{\mathrm{n}}$

Because $\dot{\mathrm{m}}_{\mathrm{ij}}=\rho \mathrm{Au}(\mathrm{kg} / \mathrm{s})$, where $u(\mathrm{~m} / \mathrm{s})$ is the crosssectional velocity between two zone divisions, as shown in Fig. 1. Therefore, in the case where $n=0.5$, the power law Equation 2 may be expressed as follow: 


$$
\frac{\mathrm{u}^{2}}{\mathrm{k}^{2}}=\Delta \mathrm{P}
$$

Thus, the cross-sectional velocity $u$ is only determined based on the nearby pressure difference, such as $\left(\mathrm{P}_{1}-\mathrm{P}_{2}\right)$, as shown in Fig. 1, since the flow coefficient $\mathrm{k}$ is a assumed to be constant.

Nevertheless, when finite difference or finite volume techniques are used to solve CFD equations, such as the Navier-Stokes momentum equations, more velocity representation of the neighboring cells need to be involved in the computation of the momentum. From the Fig. 1, other than $u, u_{1}$ and $u_{2}$ are also involved. Therefore, in addition to the assumption of a constant value $k$ used for all the zones, the simplified representation of the cross-sectional velocity $u$ in the power law model can be regarded as another major reason to limit the applications of the original zonal model to only natural convection. In the cases of forced ventilation, such as overhead ventilation system, the power law model is not able to represent the transfer of momentum effectively, because of the limited number of neighboring cells involved in the algorithm and the constant value used for the flow coefficient $k$ (Jiru, 2006).

In the new zonal model POMME, the one-dimensional momentum equation with zero viscosity (Equation 4) is used to replace the power law model (Equation 3) in order to represent the momentum relationship between the pressure difference and the velocity:

$\rho u \frac{\partial u}{\partial x}=-\frac{\partial P}{\partial x}$

where, $u(\mathrm{~m} / \mathrm{s})$ still represents the cross-sectional velocity between two zone divisions. In Equation 4, an additional term $\rho g$ is required on the right-hand side of this equation if the gravity force is applied in this direction.

In case where the finite volume technique and the staggered grid formulation are applied (Fig. 2) with the uniform mesh grid, Equation 4 can be rewritten as:

$$
(\text { puu })_{\mathrm{e}}-(\rho u u)_{\mathrm{w}}=\Delta \mathrm{P}
$$

Which is approximately equivalent to:

$$
\rho_{\mathrm{e}} \mathrm{u}_{\mathrm{e}}^{2}-\rho_{\mathrm{w}} \mathrm{u}_{\mathrm{w}}^{2}=\Delta \mathrm{P}
$$

In Equation 5, the terms $\mathrm{u}_{\mathrm{e}}$ and $\mathrm{u}_{\mathrm{w}}$ can be represented by using the velocity values of the neighboring cells, such as $u, u_{1}$ and $u_{2}$, as shown in Fig. 2. Replacing the power law model (Equation 3) with the momentum equation (Equation 5) significantly improves the zonal model, since the equation used in this new model does not include any constant coefficient. Therefore, unlike the original zonal models, this new model is suitable for both natural convection and forced ventilation cases without the involvement of additional submodels, such as jet flow model. Furthermore, in consideration of the similarity between Equation 3 and 5 and the simplicity of this model compared to the CFD models, such as the Large Eddy Simulation (LES) or the Reynolds-Average Navier-Stokes (RANS), POMME can be still categorized into the zonal model group, rather than the group of CFD models.

In this new zonal modeling approach, the mass and energy conservation equations are also used, in addition to the momentum equation (Equation 4 or 5).

Mass conservation equation for static-state problems (Fig. 3):

$$
\sum \dot{\mathrm{m}}_{\mathrm{ij}}+\dot{\mathrm{m}}_{\text {source }}+\dot{\mathrm{m}}_{\text {sin } \mathrm{k}}=0[\mathrm{~kg} / \mathrm{s}]
$$

Where:

$$
\begin{aligned}
\dot{\mathrm{m}}_{\mathrm{ij}}(\mathrm{kg} / \mathrm{s})= & \text { The rate of mass from surrounding zone } \\
& \text { to zone } \dot{\mathrm{i}}_{\mathrm{j}} \\
\dot{\mathrm{m}}_{\text {source }}(\mathrm{kg} / \mathrm{s})= & \text { The rate of mass supplied as a source in } \\
& \text { the zone, i.e., the air flow from a diffuser } \\
\dot{\mathrm{m}}_{\text {sin } \mathrm{k}}(\mathrm{kg} / \mathrm{s})= & \text { The rate of a mass removed from the } \\
& \text { zone }
\end{aligned}
$$

Energy conservation equation for static-state problems (Fig. 3):

$\sum \dot{\mathrm{q}}_{\mathrm{ij}}+\dot{\mathrm{q}}_{\text {source }}+\dot{\mathrm{q}}_{\text {sin } \mathrm{k}}=0[\mathrm{~W}]$

Where:

$\dot{\mathrm{q}}_{\mathrm{ij}}(\mathrm{W})=$ The rate of heat energy from surrounding zones to zone $i j$

$\dot{\mathrm{q}}_{\text {source }}(\mathrm{W})=$ The rate of heat energy supplied by a source in the zone

$\dot{\mathrm{q}}_{\text {sink }}(\mathrm{W})=$ The rate of heat energy removed from the zone

For transient-state problems, Equation 4-7 can be modified by respectively adding a new term $\left(\rho \frac{\partial \mathrm{u}}{\partial \mathrm{t}}, \frac{\mathrm{dM}_{\mathrm{ij}}}{\mathrm{dt}}\right.$ and $\left.\frac{\mathrm{dQ}_{\mathrm{ij}}}{\mathrm{dt}}\right)$ representing the effect of time, where $t(s)$ is time; $M_{i j}(k g)$ is the fluid mass of zone $i j$; and $Q_{i j}(J)$ is the heat energy in zone $\mathrm{ij}$. 


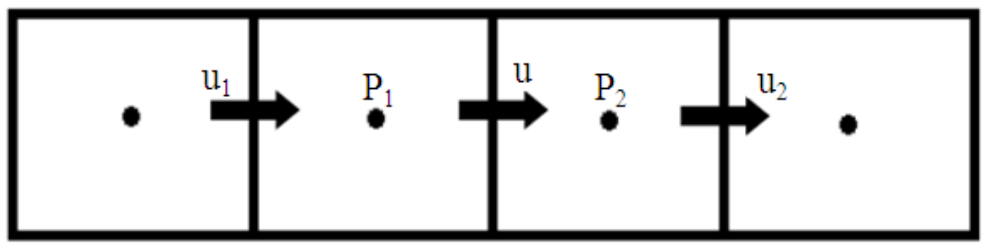

Fig. 1. Sub-zone divisions for zonal models

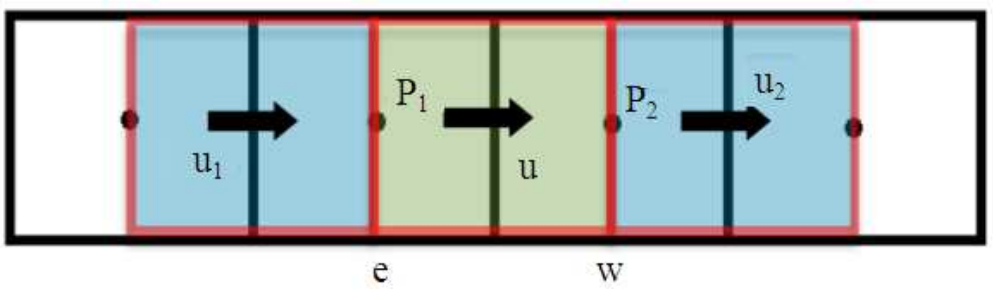

Fig. 2. Zone volumes with the staggered grid formulation

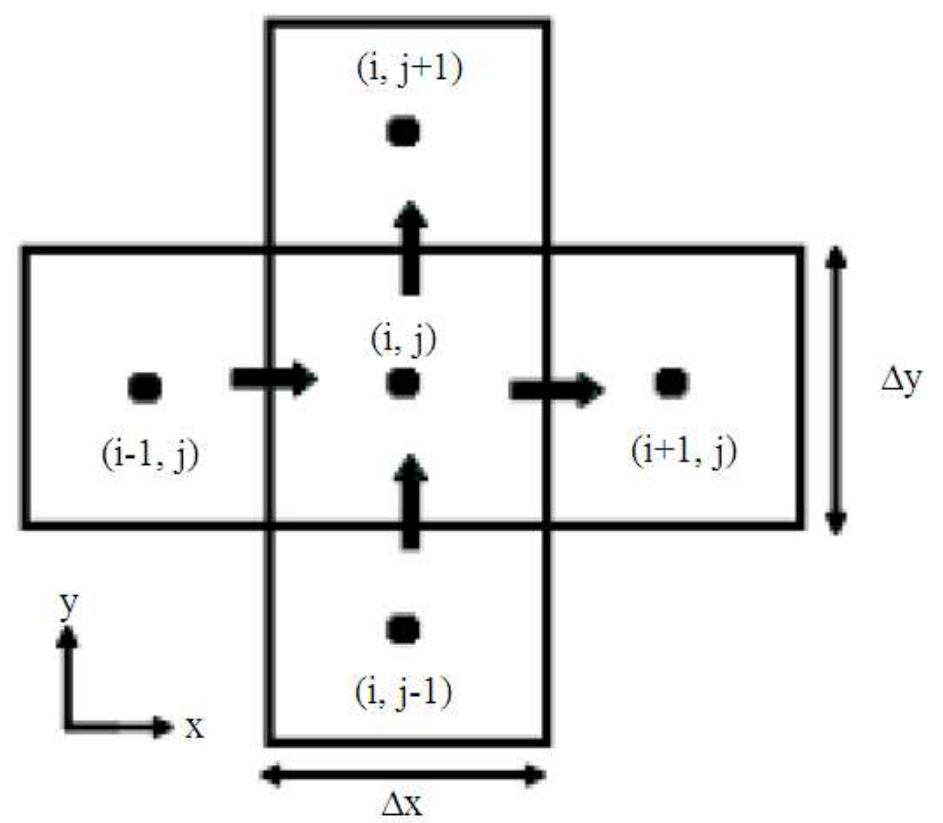

Fig. 3. Two-dimensional zone divisions

Moreover, several numerical techniques are included, i.e.,:

- $\quad$ Finite-volume numerical techniques

- $\quad$ Staggered grid formulation

- Upwind technique

- Coarse grids at the zonal model level
- Semi-Implicit Method for Pressure-Linked Equations (SIMPLE) algorithm

\section{EVALUATION OF THE NEW ZONAL MODEL}

In this section, the new zonal model POMME is validated by using the PHOENICS (2010), considering 
two situations, i.e., the cases of isothermal and nonisothermal rooms.

\subsection{The Isothermal Room Case}

The two-dimensional version of the isothermal staticstate zonal model (POMME2) is used with 60 zones subdivision, i.e., a mesh of $6 \times 10$ is considered. This isothermal room has the size of $3.1 \times 2.5 \mathrm{~m}$, as shown in Fig. 4. The supply diffuser is located high sidewall near the ceiling on the west wall and the return opening is located low sidewall near the floor on the east wall (Fig. 4). Each of the openings has the dimensions of $0.25 \times 3.1$ $\mathrm{m}$. The initial supply air flow rate is $1.5 \mathrm{~m} \mathrm{sec}^{-1}$.

Figure 5 shows the simulated airflow pattern within this room using the CFD program PHOENICS, with 1,911 cells $(39 \times 49$ mesh grid). Figure 6 shows the simulated airflow pattern using the zonal model developed POMME. As shown in these two figures, the two airflow patterns are very similar. In fact, the original zonal model POMA cannot be used to predict the airflow behavior of this room, without the help of a jet flow additional sub-model.

Figure 7 shows the comparison between POMME2 and the CFD program in terms of velocity in the $x$ direction (Fig. 4). In Fig. 7, the vertical velocity distributions over six poles in the $\mathrm{x}$ direction (the poles are vertical position evenly distributed in the room to predict the temperature distribution vertically), are used in the comparison; the $U(\mathrm{~m} / \mathrm{s})$ is the simulated $x$-direction velocity; $U_{\text {in }}(\mathrm{m} / \mathrm{s})$ is the initial supply air velocity which is $1.5 \mathrm{~m} \mathrm{~s}^{-1}$; $\mathrm{z}(\mathrm{m})$ is the elevation from the bottom of the room; and Height (m) is the height of the room space, which is $2.5 \mathrm{~m}$.

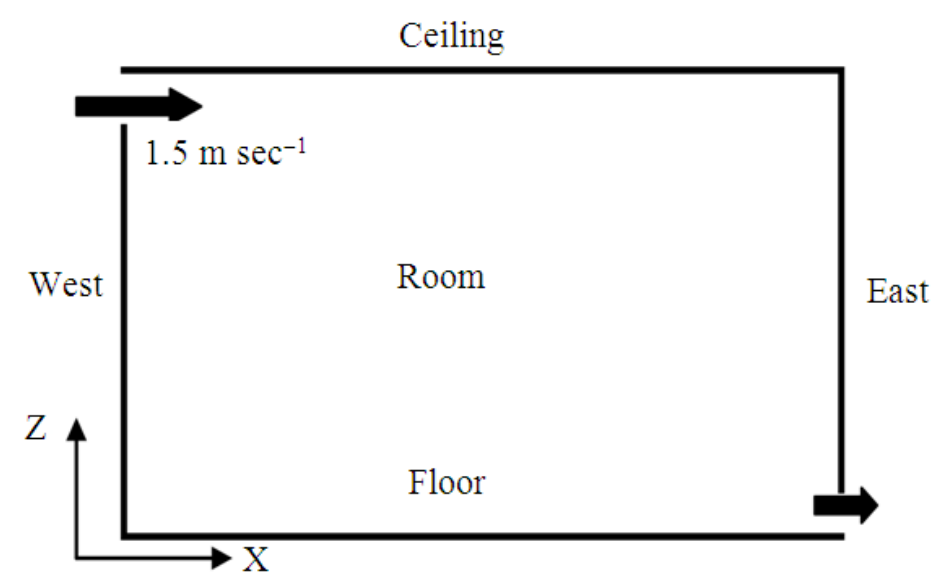

Fig. 4. The isothermal room

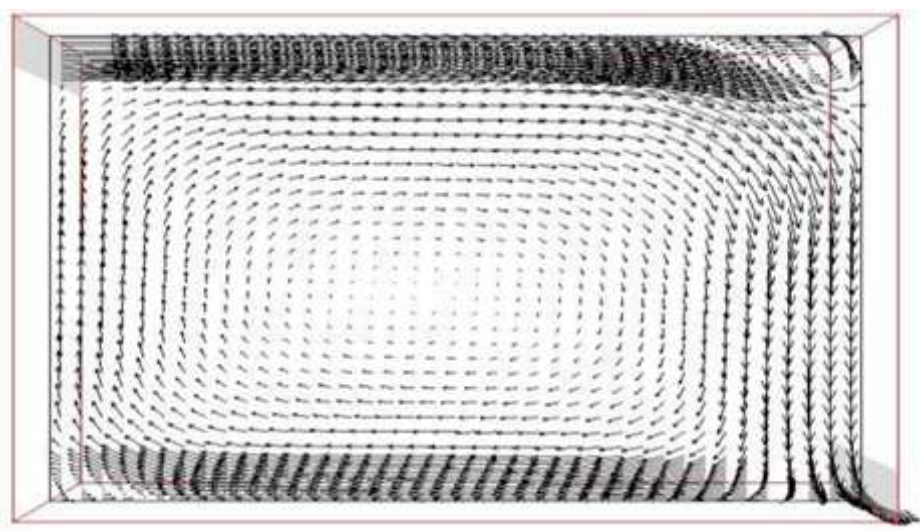

Fig. 5. Airflow pattern of the CFD model $(39 \times 49)$ 


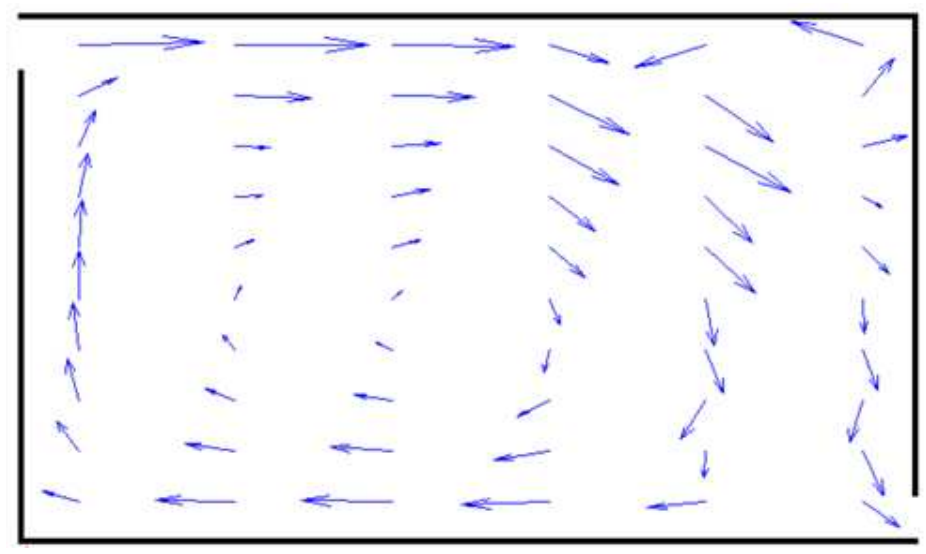

Fig. 6. Airflow pattern of the new zonal model "POMME" $(6 \times 10)$
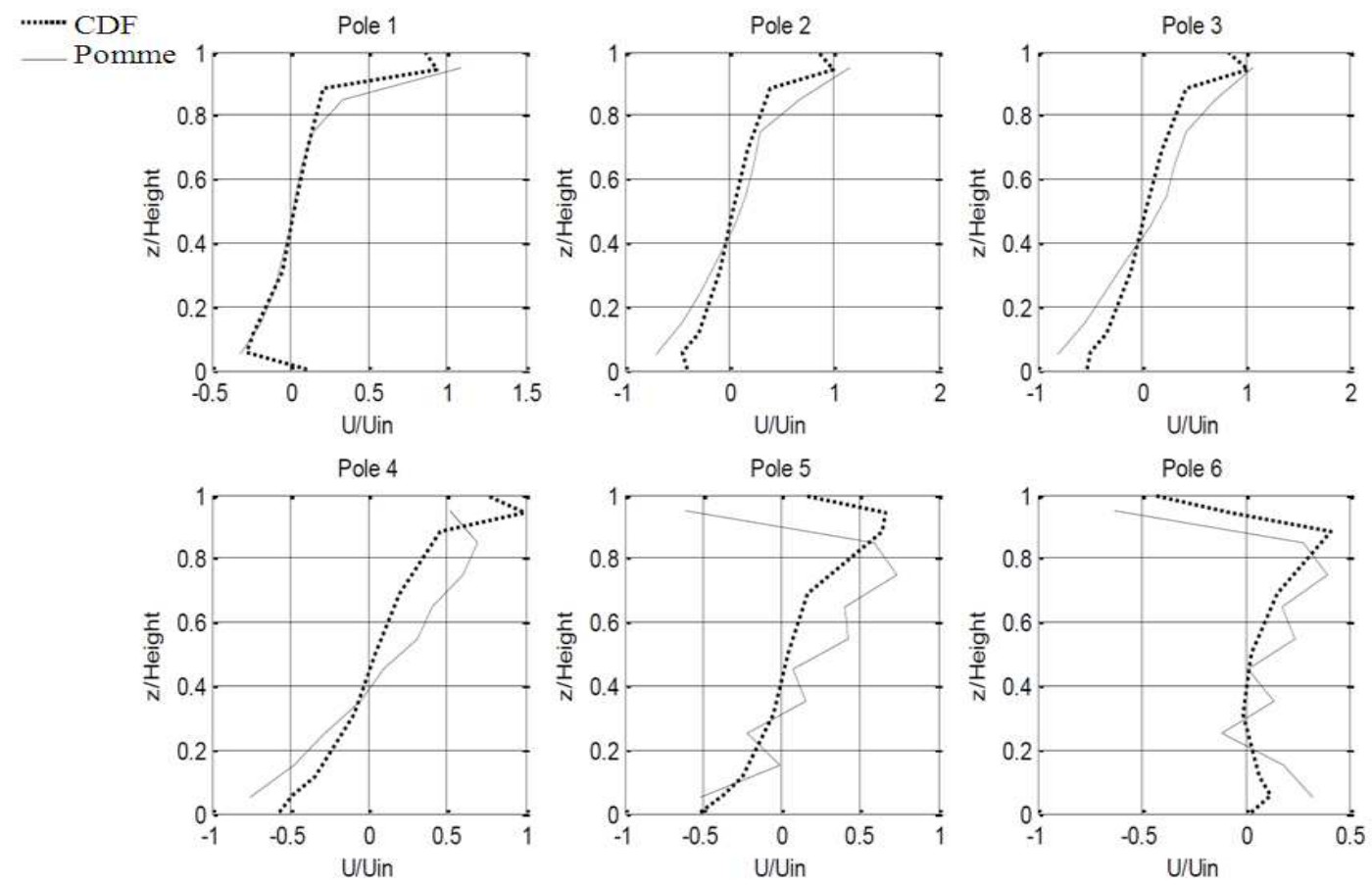

Fig. 7. Comparison between POMME and the CFD model in terms of the velocity in the $\mathrm{x}$ direction

Figure 8 shows the comparison between POMME2 and the CFD program in terms of velocity in the $\mathrm{z}$ direction (Fig. 4). In Fig. 8, W (m/s) is the simulated zdirection velocity; $U_{\text {in }}(\mathrm{m} / \mathrm{s})$ is the initial supply air velocity which is $1.5 \mathrm{~m} \mathrm{sec}^{-1}$.

As shown in Fig. 7 and 8, this new zonal model POMME2 produces a reasonably good result compared with those obtained from the CFD program, which demonstrates the ability and potential of this model to predict airflow behavior without the usage of the jet flow model for the two-dimensional forced ventilation case.

\subsection{The Non-Isothermal Room Case}

The three-dimensional version of the non-isothermal static-state zonal model (POMME3) is used. This simulated non-isothermal room (Fig. 9) has the dimensions of $3.1 \times 3.1 \times 2.5 \mathrm{~m}$. The supply diffuser is located high sidewall near the ceiling on the west wall 
and the return opening is located low sidewall near the floor on the east wall. Both of them have the dimensions of $0.25 \times 3.1 \mathrm{~m}$. The initial supply air flow rate is $1.5 \mathrm{~m} \mathrm{sec}^{-1}$; the initial supply air temperature is $29^{\circ} \mathrm{C}$; and the boundary conditions (room interior surface temperatures) are shown in Table 1. In this model, 60 cells $(6 \times 1 \times 10$ mesh grid $)$ are used. Considering the fact that the temperature boundary conditions of the north and south wall surfaces are close to each other (Table 1) and both the diffuser and return opening are uniformly distributed in the northsouth direction, thus just one zone was used in the north-south direction.

Figure 10-12 show the comparison between POMME3 and the CFD program with 74,529 cells $(39 \times 39 \times 49$ mesh grid) in terms of the $x$-direction velocity, the $\mathrm{z}$-direction velocity and the room air temperature, respectively. In these figures, the vertical distributions over the six poles, which are evenly distributed in the room (Fig. 9), are used in the comparison.
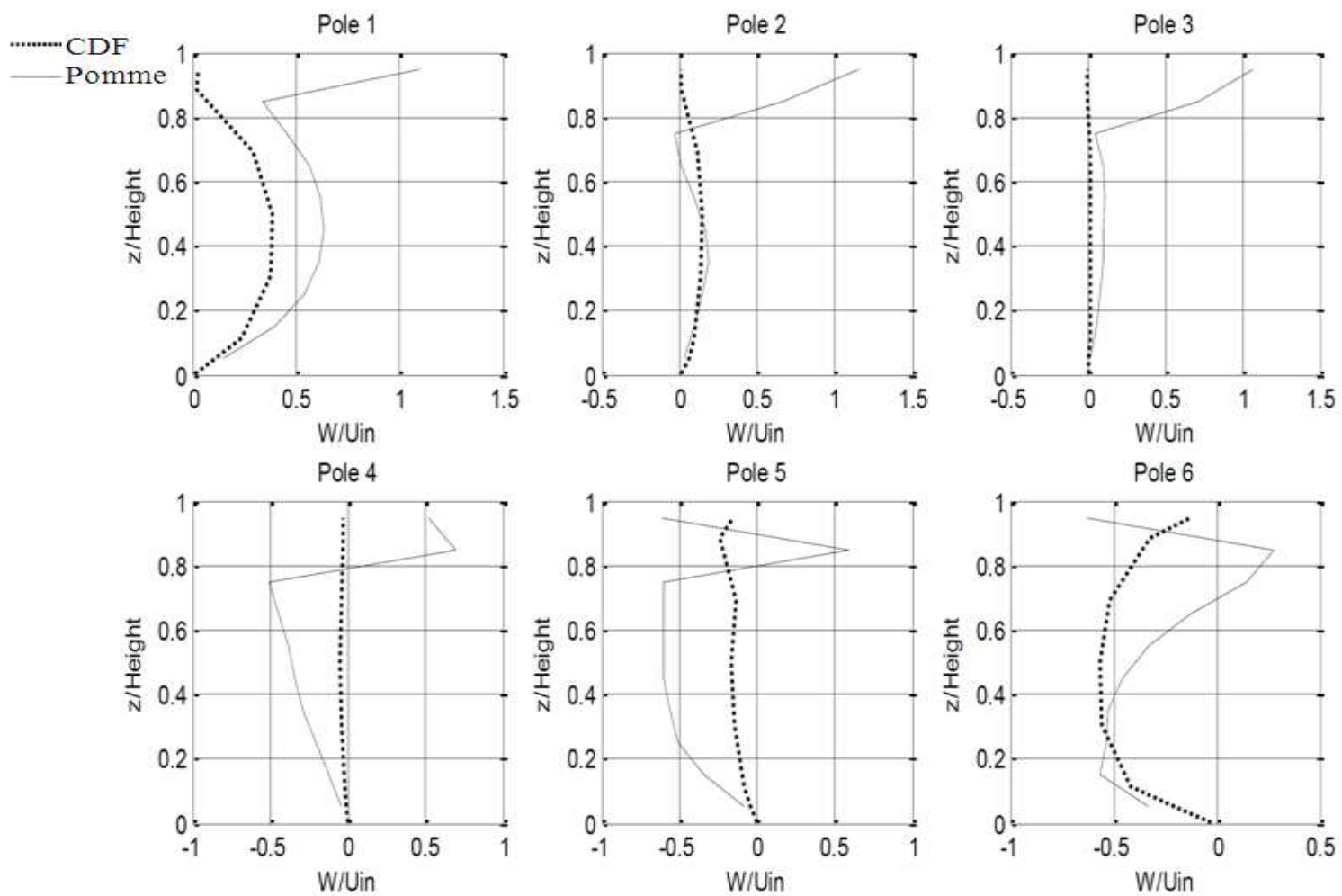

Fig. 8. Comparison between POMME and the CFD model in terms of the velocity in the $\mathrm{z}$ direction

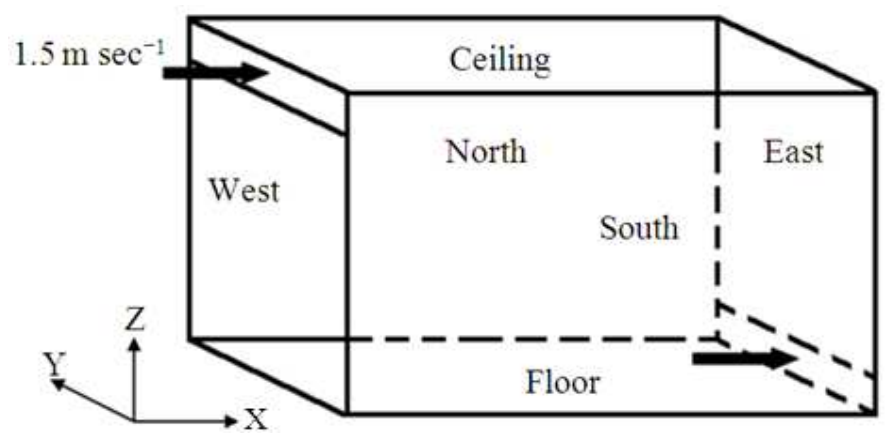

Fig. 9. The non-isothermal room 

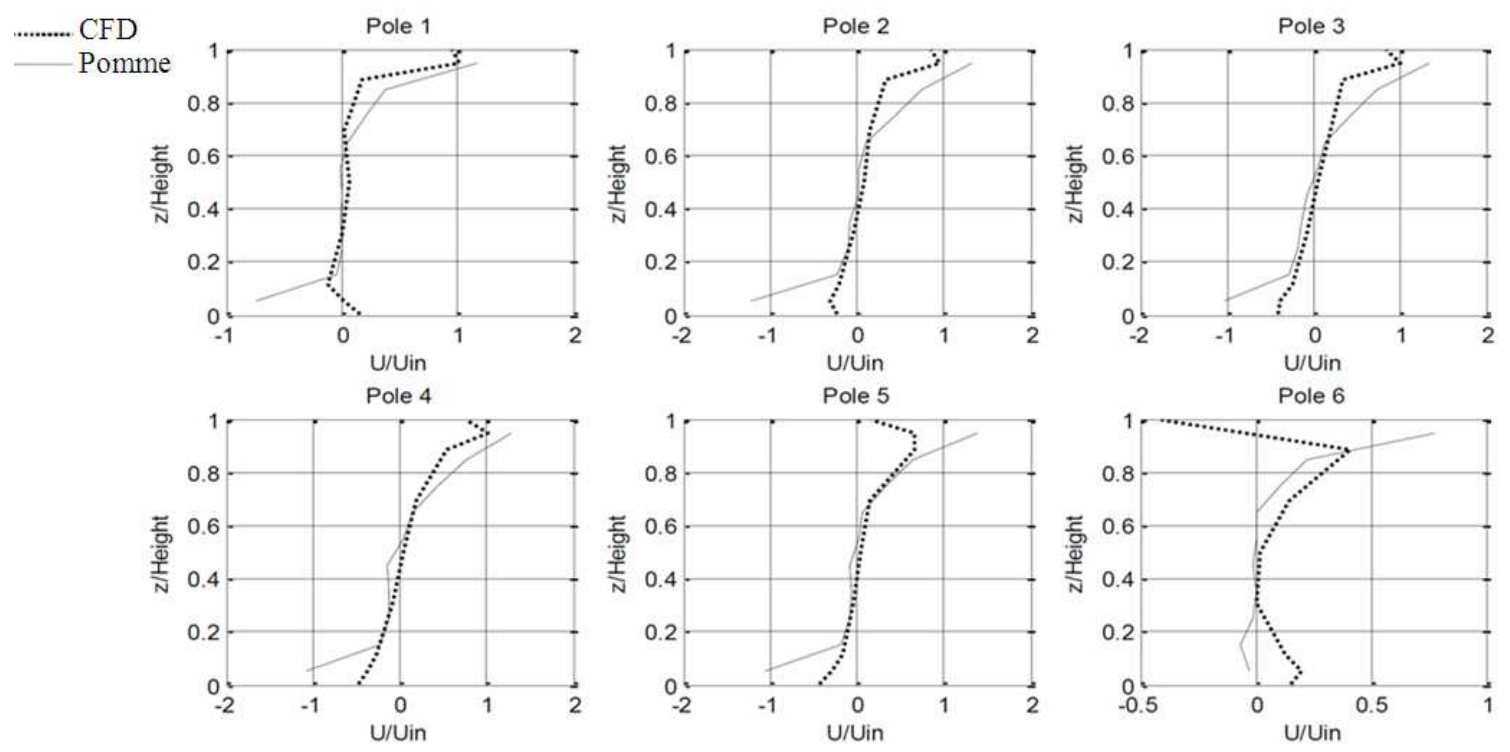

Fig. 10. Comparison between POMME and the CFD model in terms of the velocity in the $\mathrm{x}$ direction
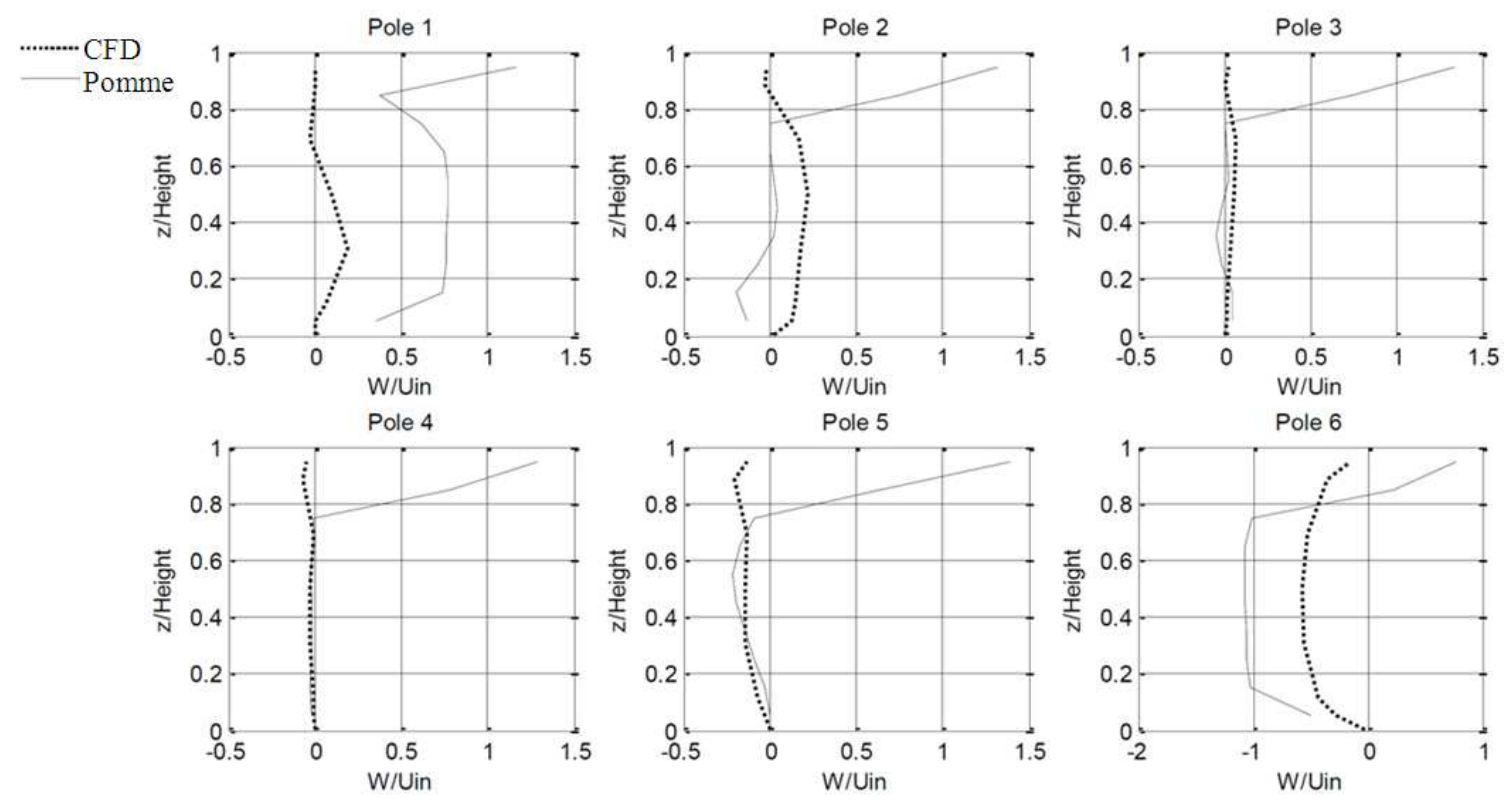

Fig. 11. Comparison between POMME and the CFD model in terms of the velocity in the $\mathrm{z}$ direction

As shown from these three figures, good agreements are achieved between the results of the new zonal model and the CFD program in terms of room air velocity (Fig. 10 and 11) and room air temperature (Fig. 12). The non-isothermal room air temperature distributions on the medium plane of the $y$ direction predicted using POMME3 and the CFD program are shown in Fig. 13 and 14, respectively. As shown in these two figures, an acceptable prediction result in terms of room air temperature was produced by POMME3, especially in the central space of the room. 
Yao Yu and Ahmed Cherif Megri / American Journal of Engineering and Applied Sciences 7 (1): 77-87, 2014
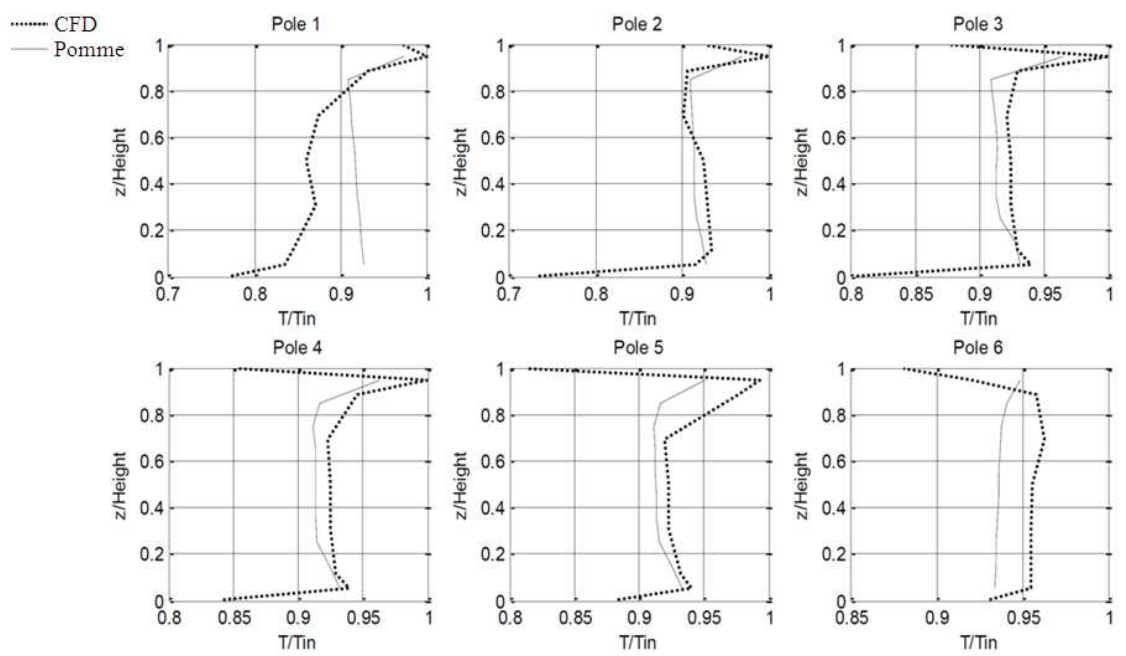

Fig. 12. Comparison between POMME and the CFD model in terms of the room air temperature

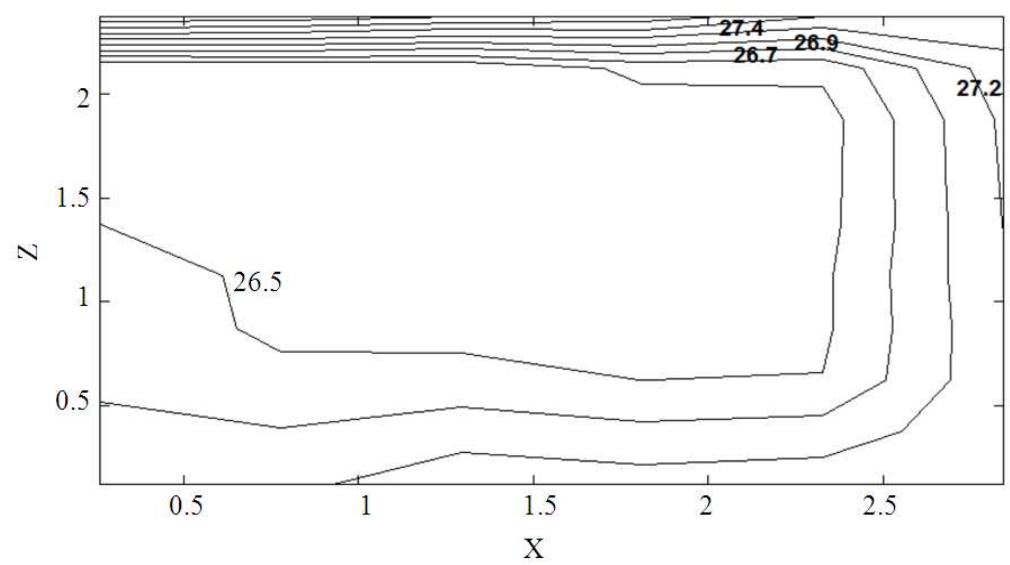

Fig. 13. Temperature distribution $\left[{ }^{\circ} \mathrm{C}\right]$ predicted using POMME

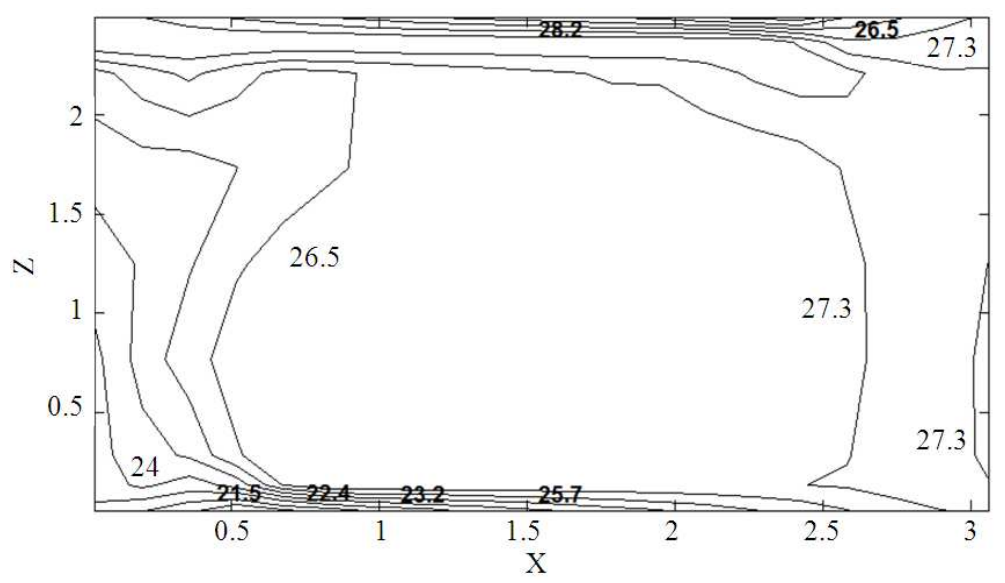

Fig. 14. Temperature distribution $\left[{ }^{\circ} \mathrm{C}\right]$ predicted using CFD 
Table 1. Boundary conditions for the non-isothermal case

\begin{tabular}{lllllll}
\hline & East $\left[{ }^{\circ} \mathrm{C}\right]$ & West $\left[{ }^{\circ} \mathrm{C}\right]$ & South $\left[{ }^{\circ} \mathrm{C}\right]$ & North $\left[{ }^{\circ} \mathrm{C}\right]$ & Ceiling $\left[{ }^{\circ} \mathrm{C}\right]$ & Floor $\left[{ }^{\circ} \mathrm{C}\right]$ \\
\hline Temperature & 13.9 & 6.0 & 14.1 & 14.1 & 13.5 & 11.8 \\
\hline
\end{tabular}

\section{DISCUSSION}

In fact, the evaluation performed on POMME for both isothermal and non-isothermal cases demonstrate the strength of POMME to predict the indoor airflow and temperature distribution without the involvement of additional sub-models.

Although, at the boundary regions of the room, near the room interior surfaces, the zonal model results do not match completely the results of the CFD model, such as the results of the poles 1 and 6 and also when the value of $z /$ Height is close to zero or one (near the floor and ceiling), these regions are outside the occupied space and therefore are not significant compared to the space where people's activities take place. Usually, the room occupied space is defined as the space beyond 1 foot of the walls and within 6 feet from the floor. In fact, the mismatch of the results between POMME and the CFD program at the boundary regions is caused by the simplified equations used by the model POMME to describe the momentum variation, such as the ignorance of the viscosity terms and the usage of simplified one dimensional momentum equation for twoor three- dimensional problems. Although these simplifications used in POMME model simplify the model structure and thus reduce the corresponding computational time, they may make the model difficult to provide acceptable predictive result for airflow with high turbulence, which is the limitation of the new zonal model POMME used for building enclosure. Generally, the airflow in buildings is characterized with low turbulence in order to maintain the appropriate thermal comfort levels. Therefore, in building environment, the new zonal model POMME can be regarded as an alternative to CFD programs, especially to predict the air flow and thermal behaviors in room occupied space.

Another reason that causes the mismatch at the boundary regions is the usage of coarse grid in POMME. The airflow in the regions near the room interior surfaces is not stable comparatively to the airflow in the occupied space because of the existence of boundary layers. Actually, if the size of the mesh grid at the boundary regions is not tightened enough, the flow and thermal characteristics of the boundary layers are not effectively captured.

\section{CONCLUSION}

A new zonal model POMME has been developed by using a one-dimensional momentum equation with zero viscosity, instead of the power law model, usually used for zonal models. Unlike the existing zonal models, the new model can be used for both natural convection and forced ventilation cases without involving additional sub-models. The evaluation of the new zonal model has been accomplished by the comparison of the results of POMME with those obtained by the CFD program PHOENICS, for single room cases, isothermal and non-isothermal. The evaluation results show that the new model is capable of providing relatively accurate predictions for the room central space that is known as the occupied space in which people's activities take place. Although there exist limitations of this new zonal model, especially for the prediction of air flow and thermal behaviors at the room boundary regions, as a matter of fact, this new zonal model not only simplifies the complexity of the model used in forced ventilation cases, but also maintains the basic characteristics of zonal model compared to CFD models. The future research of this new zonal model involves further investigation to improve the model prediction for two- and three-dimensional static- and transient-state applications.

\section{REFERENCES}

Axley, J.W., 2001. Surface-drag flow relation for zonal modeling. Build. Environ., 36: 843-850. DOI: 10.1016/S0360-1323(01)00010-5

Bouia, H., 1993. Modélisation simplifiée d'écoulements de convection mixte interne: Application aux échanges thermo-aérauliques dans les locaux. Ph.D. Thèse Université de Poitiers, France.

Griffith, B. and Q.Y. Chen, 2003. A momentum-zonal model for predicting zone airflow and temperature distributions to enhance building load and energy simulations. HVAC\&R Res., 9: 309-325. DOI: 10.1080/10789669.2003.10391072

Haghighat, F., Y. Lin and A.C. Megri, 2001. Development and validation of a zonal modelPOMA. Build. Environ., 36: 1039-1047. DOI: 10.1016/S0360-1323(00)00073-1

Inard, C. and D. Buty, 1991. Simulation and thermal coupling between a radiator and a room with zonal models. Proceedings of the Building Simulation, (PBS' 91), Nice, France, pp: 113-117. 
Inard, C. and N. Molle, 1989. Le chauffage par corps de chauffe: Efficacité en confort et en consommation. Revue Générale de Thermique, 28: 650-656.

Inard, C., H. Bouia and P. Dalicieux, 1996b. Prediction of air temperature distribution in buildings with a zonal model. Energy Build., 24: 125-132. DOI: 10.1016/0378-7788(95)00969-8

Inard, C., P. Depecker and J.J. Roux, 1997a. Un modèle simplifié pour la prédiction du champ de temperature dans les bâtiments. Revue Générale de Thermique, 36: 113-123. DOI: 10.1016/S00353159(99)80056-7

Inard, C., A. Meslem and P. Depecker, 1996a. Use of a zonal model for the prediction of air temperature distribution in large enclosures. Proceedings of the 5th International Conference on Air Distribution in Rooms, Jul. 17-19, Yokohama, Japan.

Inard, C., A. Meslem, P. Depecker and P. Barles, 1997b. Structure moyenne et analyse intégrale du panache thermique des convecteurs électriques. Revue Générale de Thermique, 36: 495-509. DOI: 10.1016/S0035-3159(97)84033-0

Jiru, T.E., 2006. A new generation of zonal models: Development, verification and application. Ph.D. Thesis, Department of Building, Civil and Environmental Engineering, Concordia University, Montreal, Quebec, Canada.
Jiru, T.E. and F. Haghighat, 2004. Zonal models for indoor air flow-A critical review. Int. J. Ventilat., 3: 119-129.

Lebrun, J., 1970. Exigences physiologiques et modalités physiques de la climatisation par source statique concentrée. Ph.D. Thesis, University of Liège, Belgium.

Megri, A.C. and F. Haghighat, 2007. Zonal modeling for simulating indoor environment of buildings: Review, recent developments and applications. HVAC\&R Res., 13: 887-905. DOI: 10.1080/10789669.2007.10391461

Megri, A.C., M. Snyder and M. Musy, 2005. Building zonal thermal and airflow modelling-A review. Int. J. Ventilat., 4: 177-188.

Phoenics, 2010. Phoenics-VR Reference Guide. CHAM.

Wurtz, E., 1995. Modélisation tridimensionnelle des transferts thermiques et aérauliques dans le bâtiment en environnement oriente objet. Ph.D. Thesis, Ecole Nationale des Ponts et Chausses, Marne-la-Vallée, France.

Yu, Y., 2012. Zonal modeling approach and its applications in buildings. MSc. Thesis, Department of Civil and Architectural engineering, University of Wyoming, USA. 